HortSCIENCE 27(5):416-419. 1992.

\title{
Air Sampling of Volatiles from Agaricus bisporus in a Mushroom Facility and from Mushroom Compost
}

Richard M. Pfeil' ${ }^{1}$ and Ralph O. Mumma

Pesticide Research Laboratory and Graduate Study Center, Department of Entomology, The Pennsylvania State University, University Park, PA 16802

Additional index words. volatiles, 3-octanone, 1-octen-3-ol, Tenax, Megaselia halterata, phorid fly

Abstract. Air sampling using Tenax, a selective solid absorbent, was performed from spawning to pinning over the duration of four mushroom crops of Agaricus bisporus (Lange) Imbach (Fungi; Agricaceae). The contents of the air sampling tubes were thermally desorbed directly to a gas chromatograph-mass selective detector. In two crops 3-octanone and 1-octen3-ol were detected 12 to 13 days after spawning. These two compounds were also detected after compost was added at casing (CAC) and the ketone was present in large quantities. Air sampling of a 10-g sample of spawned compost vs. unspawned compost confirmed that these two compounds were of fungal origin. Bags of spawned compost were used to determine the effects of a CAC layer, a soybean supplement, and Spawn Mate on the volatiles released by the spawned compost. The CAC layer and the soybean supplement selectively absorbed 1-octen-3ol and, to a lesser extent, 3-octanone. The addition of Spawn Mate to the compost at spawning did not alter the quantity or ratio of 3-octanone to 1-octen-3-ol released by the spawned compost.

The phorid fly [Megaselia halterata (Wood) (Phoridae: Diptera)] is primarily attracted to

Received for publication 26 Nov. 1991. Accepted for publication 13 Jan. 1992. We thank Daniel J. Royse and John Winnett for their assistance with this research. We also thank the Dept. of Plant Pathology for the use of the MTDF and for the spawned compost. The cost of publishing this paper was defrayed in part by the payment of page charges. Under postal regulations, this paper therefore must be hereby marked advertisement solely to indicate this fact.

Current address: Environmental Chemistry Laboratory U.S. Dept. of Agriculture, Agricultural Research Service, Bldg. 001, BARC-West, 10300 Baltimore Ave., Beltsville, MD 20705-2350. colonized mushroom compost at 11 to 14 days after spawning (Hussey, 1959). Megaselia halterata caused severe damage to the mushroom industry in Europe in the 1950s (Moreton, 1954) and in the United States during the past 6 years (Barber and Cantarera, 1987). The interaction of actively growing Agaricus bisporus with compost has been implicated, but not proven, as being the source of volatile attractants for female $M$. halterata (Hussey, 1959; Moreton, 1954). From laboratory and mushroom house experiments, increasing levels of colonization of compost by fungal mycelia increases the attractiveness of the compost up to 14 days after the start of fungal colonization (Hussey, 1961). 
After this time, the number of eggs deposited declines rapidly. Hussey (1961) and Grove and Blight (1983) indicated that an increase in the concentration of volatiles may be involved in the attractiveness of the spawned compost to M. halterata. Grove and Blight (1983) tentatively reported that 1-octen-3-ol, 1-octen-3-one, and 3-octanol are attractive to gravid female $M$. halterata.

Air sampling was performed at the Mush-
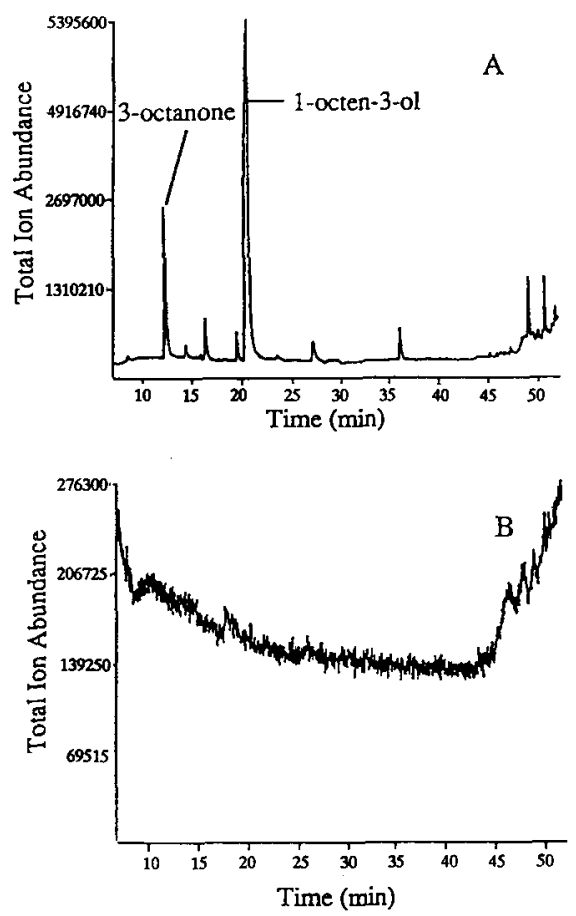

Fig. 1. Total ion abundance chromatograms of $10 \mathrm{~g}$ spawned (A) and unspawned mushroom compost (B).

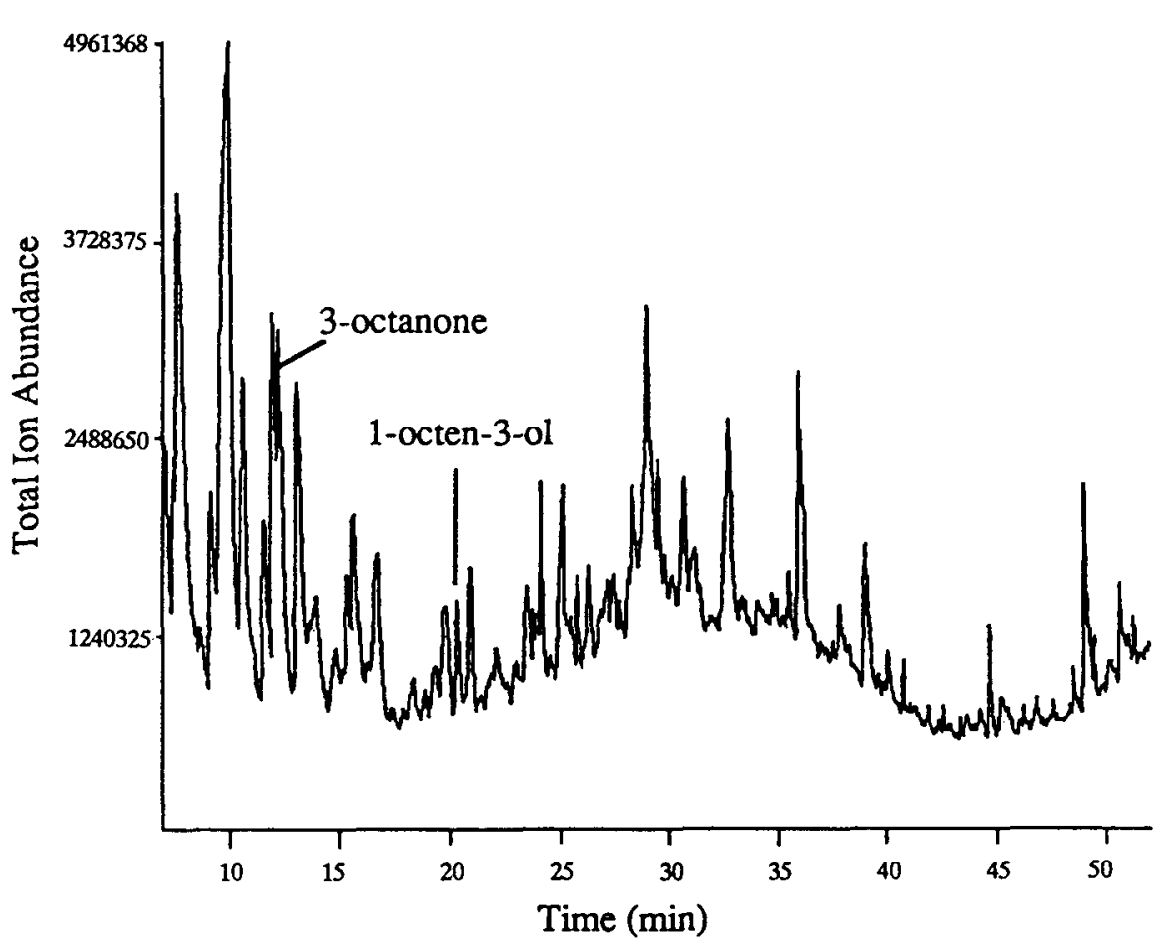

Fig. 2. A typical total ion abundance chromatogram of air sampled 12 to 13 days after spawning of mushroom crop 2 at the Mushroom Test Demonstration Facility.

room Test Demonstration Facility (MTDF), The Pennsylvania State Univ., to determine the types of compounds produced by spawned compost on a large-scale basis and to track the evolution of the volatiles over time from spawning through pinning. Bags of spawned compost were also used to determine the effects of compost added at casing (CAC), a soybean supplement, and Spawn Mate (Spawn Mate, Capitola, Calif.) on the volatiles released by the spawned compost. Spawn Mate is a compost supplement that is high in linoleic acid, the supposed precursor to 3-octanone and 1-octen-3-ol (Wurzenberger and Grosch, 1982, 1984a, 1984b).

Cultivation of $A$. bisporus. The cultivation of four crops of $A$. bisporus (Table 1) at the MTDF involved several steps, including: preparation of the compost, spawning, CAC, and pinning. The preparation of the compost involved two phases. In phase I, wheat straw, horse and chicken manure, gypsum, and brewer's grain were composted for 7 days (Schisler, 1982). Phase II consisted of the following three functions: 1) pasteurization, 2) deammonification, and 3) final conditioning of the compost. Pasteurization was accomplished by holding the compost temperature at $60 \mathrm{C}$ for at least $2 \mathrm{~h}$. The compost was held at 46 to $57 \mathrm{C}$ for $\geq 96 \mathrm{~h}$ after pasteurization to encourage desirable thermophilic microbes to become well-established in the compost. Deammonification and conditioning of the compost occurred after pasteurization.

The finished compost was cooled to $\approx 29 \mathrm{C}$ and spawned (Table 1). Spawn is sterilized seeds [i.e., rye (Secale cereale L.)] that has been completely colonized by the mycelia of A. bisporus and is used to establish the mushroom mycelia in the compost. After $\approx 13$ days of growth at $24 \mathrm{C}$, the spawned compost

HortScience, Vol. 27(5), May 1992 was well colonized by A. bisporus. To replenish the nutrient-depleted compost, a soybean supplement was mixed into the compost before the addition of a CAC layer. Peatmoss, ground limestone, and finely chopped spawned compost were mixed together to make a CAC layer (Table 1) that was spread on top of the colonized compost to a depth of $\approx 8 \mathrm{~cm}$. The CAC compost was then moved into the set-back room. The $\mathrm{CO}_{2}$ level of the air in the set-back room built up to 10,000 to $15,000 \mathrm{ppm}$ before pinning (formation of mushroom pins). Fresh air was not forced into the set-back room until pinning had occurred. At 6 to 7 days after CAC, the setback room was continuously flushed with fresh air and the compost temperature was lowered to 19C.

The spawned compost used in the bag experiments was obtained from the MTDF. Sixteen pleated clear plastic bags (6 liters) were filled with $5 \mathrm{~kg}$ of spawned compost and maintained at 18 to $21 \mathrm{C}$ in a Sherer growth chamber (Model Cel 3714; ShererGillett, Marshal, Mich.). In another experiment, half of the bags of spawned compost were supplemented with Spawn Mate at a rate of $90 \mathrm{~g} / 5 \mathrm{~kg}$ spawned compost (the manufacturer's recommended supplement rate). The Spawn Mate was well-mixed into the compost by hand after the compost had been spawned at the MTDF.

Air sampling. An air sampling tube consisted of a glass tube $(7 \mathrm{~cm}$ long $\times 4 \mathrm{~mm}$ i.d. $\times 6 \mathrm{~mm}$ o.d.) packed with $100 \mathrm{mg}$ of Tenax (60 to 80 mesh) (Supelco, Bellefonte, Pa.). A Dynatherm Model 850 thermal desorption unit (Supelco) was used in conjunction with a Hewlett Packard 3700 Gas Chromatograph-5970 Mass Selective Detector (GC-MSD; Hewlett Packard, Valley Forge, Pa.) in the analyses of volatiles. A $30 \mathrm{M}$ Stabilwax capillary column $(0.25 \mathrm{~mm}$ i.d., $0.25 \mu \mathrm{m}$ film thickness, Crossbonded Carbowax PEG 20 M; Restek Corp., Bellefonte, $\mathrm{Pa}$.) provided the separation of the desorbed volatiles. After a 6-min hold at $35 \mathrm{C}$, a temperature program of $3 \mathrm{C} / \mathrm{min}$ up to $200 \mathrm{C}$ was used. Helium was used as the desorption gas at a flow rate of $12 \mathrm{ml} \cdot \mathrm{min}^{-1}$ and the carrier gas at a flow rate of $1 \mathrm{ml} \cdot \mathrm{min}^{-1}$.

A Nesbitt absorption chamber (Kimble product no. 16010; Kimble, Montclair, N.J.) was adapted for air sampling of a 10-g sample of compost. The compost was sampled at an air flow rate of $120 \mathrm{ml} \cdot \mathrm{min}^{-1}$ for 5 min. At this flow rate, the volume of air in the sampling device was replaced six times.

Air was sampled periodically at the MTDF. Two sets of absorption tubes were used for each sampling period. Each set consisted of a main tube and a break-through tube connected end-to-end to each other with a Swagelock union fitted with 6-mm ferrules. The sampling tubes were inserted through the slats of the top tray of a stack of compost trays. The tubes were suspended $5 \mathrm{~cm}$ above the spawned compost. A De Vilbiss air pump (De Vilbiss Co., Somerset, Pa.) was used to pull air through the tubes. Airflow rate was determined by using a bubble meter and was regulated by a needle valve. The air sam- 
Table 1. Description of mushroom (Agaricus bisporus) crops air-sampled at the Mushroom Test Demonstration Facility.

\begin{tabular}{cccccccc}
\hline \hline Crop & Spawn & $\begin{array}{c}\text { Supplements } \\
\text { for compost }(\mathrm{kg})\end{array}$ & $\begin{array}{c}\text { Volume of straw } \\
\left(\mathrm{m}^{3}\right)\end{array}$ & $\begin{array}{c}\text { Compost }(\mathrm{kg}) \\
(\% \text { moisture) }\end{array}$ & $\begin{array}{c}\text { Spawn } \\
(\mathrm{kg})\end{array}$ & $\begin{array}{c}\text { CAC } \\
\text { supplement } \\
(\mathrm{kg} \text {, soybean) }\end{array}$ & $\begin{array}{c}\text { CAC } \\
\mathrm{material}^{\mathbf{z}}\end{array}$ \\
\hline 1 & $\begin{array}{c}\text { MSL hybrid } \\
\text { Off-white }\end{array}$ & $181 / 136 / 181^{y}$ & 36 & $4528(71)$ & 67 & $\cdots--$ & $\ldots$ \\
2 & $\begin{array}{c}\text { Amycel hybrid } \\
\text { White 3 }\end{array}$ & $136 / 136 / 181^{y}$ & 41 & $4657(72)$ & 70 & 110 & $1.2 / 127 / 34$ \\
3 & $\begin{array}{c}\text { Lambert hybrid } \\
\text { Off-White 501 }\end{array}$ & $136 / 136 / 136^{x}$ & 41 & $5237(73)$ & 65 & 127 & $1.2 / 127 / 34$ \\
4 & Guthrie's White & $68 / 136 / 136^{x}$ & 35 & $6127(72)$ & 107 & 128 & $1.4 / 145 / 45$ \\
\hline
\end{tabular}

${ }^{2}$ Cubic meters of peatmoss/kilogram of limestone/kilogram of spawned compust.

×Acto 88/gypsum/brewer's grain; Acto 88 is a commercial mushroom supplement, manufactured by Mushroom Supply Co., Toughkenamon, Pa.

'Dried poultry manure/gypsum/brewer's grain.

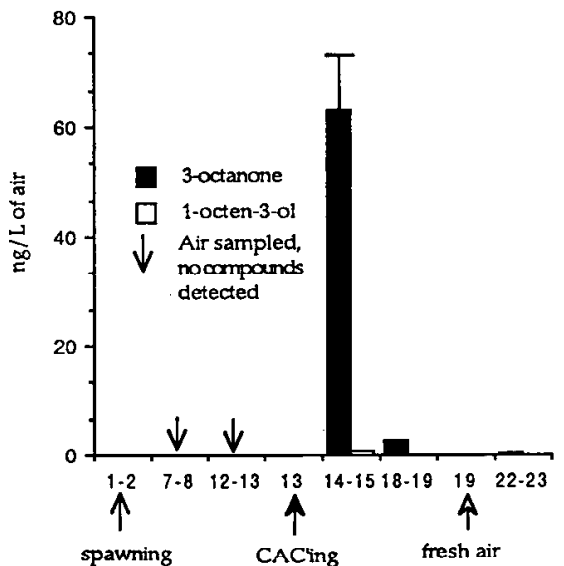

Days from Spawning

Fig. 3. Mean levels of 3-octanone and 1-octen3-ol detected by periodic air sampling of mushroom crop 3 at the Mushroom Test Demonstration Facility.

pling was performed at $300 \mathrm{ml}$ of air/minute.

The spawned compost contained in bags was used in the following treatments: A, spawned compost was not physically moved or disturbed after the spawning date, sampled for $9 \mathrm{~h}$; B, $10 \mathrm{~g}$ of colonized compost was sampled before treatments C, D, and E; $\mathrm{C}$, colonized compost mixed, sampled for 1 h; D, colonized compost mixed, sampled for $9 \mathrm{~h}$; E, colonized compost mixed/CAC, sampled for $9 \mathrm{~h}$; and $\mathrm{F}$, colonized compost mixed/CAC/supplement added, sampled for $9 \mathrm{~h}$. All treatments were completely randomized within the growth chamber. Ten grams of spawned compost was removed from bags used in treatments $\mathrm{C}, \mathrm{D}$, and $\mathrm{E}$, and the volatiles from these 10-g samples were absorbed on Tenax as described above. Soybean supplement (100 g) was added to bags of treatment F. Sufficient amounts of CAC were used for bags in treatments $\mathrm{E}$ and $\mathrm{F}$ to create an 8-cm CAC layer.

The spawned compost contained in bags was air-sampled at a flow rate of $300 \mathrm{ml} \cdot \mathrm{min}^{-1}$. Air sampling was started immediately after treatment of the bags of compost and no breakthrough tubes were used. The sampling tube was enclosed in the bag by wrapping the top of the bag around the tube. Air sampling of bags was performed with the same equipment used for air sampling at the MTDF.

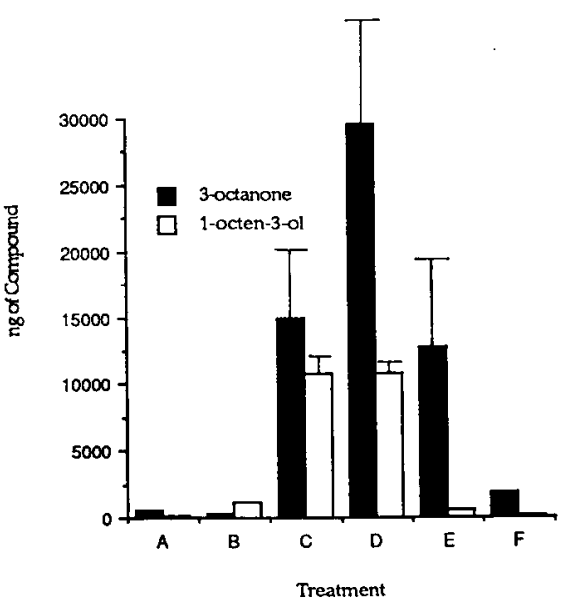

Fig. 4. Mean levels of 3-octanone and 1-octen3-ol detected by air sampling of mushroom compost contained in bags. Treatment $A$, nondisturbed compost; B, $10 \mathrm{~g}$ spawned compost sampled before treatment; $C$, bag of spawned compost mixed, sampled for $1 \mathrm{~h} ; \mathrm{D}$, bag of spawned compost mixed, sampled for $9 \mathrm{~h}$; E, bag of spawned compost mixed/CAC, sampled for $9 \mathrm{~h}$; and $\mathrm{F}$, bag of spawned compost mixed/ $\mathrm{CAC}$ and supplement added, sampled for $9 \mathrm{~h}$.

Air sampling of a 10-g sample of spawned compost. Sampling of air over a $10 \mathrm{-g}$ sample of colonized compost (spawned for 12 to 13 days) yielded two major compounds that were not present in the unspawned compost (Fig. $1 \mathrm{~A}$ and B). Identification of the compounds was made by comparison of retention times of standards with those of the unknown compounds and by computer match of mass spectra. The two compounds were identified as 3-octanone and 1-octen-3-ol.

Tracking of 3-octanone and 1-octen-3-ol over time at the MTDF. No detectable amounts of 3-octanone and 1-octen-3-ol were emitted during the first 8 to 9 days after spawning in all of the crops sampled. After 12 to 13 days from spawning, small amounts of 3-octanone were emitted by crops 1 (2.4 and $5.3 \mathrm{ng} \cdot$ liter $^{-1}$ of air) and 2 (3.9 and 5.0 ng.liter ${ }^{-1}$ of air). Only in crop 2 was a small amount of 1-octen-3-ol (0.5 and 0.9 ng.liter ${ }^{-1}$ of air) detected (Fig. 2). Air sampling of crops 3 and 4 did not detect 3-octanone or 1-octen-3-ol at 12 to 13 days after spawning.

Crops 2, 3, and 4 were air-sampled for volatiles from spawning through pinning. Large amounts of 3-octanone were emitted

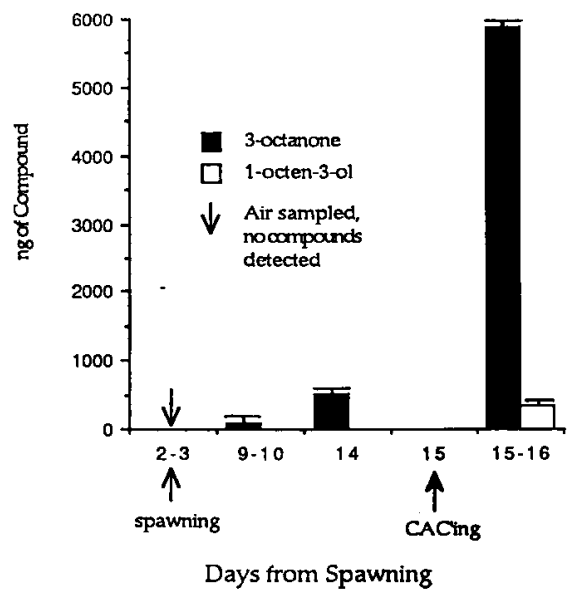

Fig. 5. Mean levels of 3-octanone and 1-octen3-ol detected by periodic air sampling of mushroom compost (contained in bags) supplemented with Spawn Mate.

(Fig. 3) after CAC was performed on crops 3 (74.0 and $52.5 \mathrm{ng} \cdot$ liter $^{-1}$ of air) and 4 (42.5 and $25.1 \mathrm{ng} \cdot \operatorname{liter}^{-1}$ of air). In addition to 3octanone, low levels of 1-octen-3-ol were found in crop 3 (0.74 and $0.6 \mathrm{ng} \cdot$ liter $^{-1}$ of air).

The level of 3-octanone dropped rapidly 5 to 6 days after CAC. In crop 3, the level of 3-octanone had dimished to $3.6 \mathrm{ng} \cdot$ liter $^{-1}$ of air and was not detectable in crop 4. Although crop 2 was not sampled the day after CAC, 3-octanone was detected (2.3 ng.liter ${ }^{-1}$ of air) 3 to 4 days after CAC. In crop 3, a small amount of 3-octanone ( 0.4 ng.liter ${ }^{-1}$ of air) was detected 2 days after fresh air was brought into the setback room.

Since a large amount of 3-octanone was released after CAC, a comparable amount of 1-octen-3-ol was also expected after CAC in comparison to the sampling of $10 \mathrm{~g}$ of spawned compost. However, little or no 1octen-3-ol was detected at this time. Also, a large amount of 3-octanone must have been emitted 9 to 10 days after CAC of crop 3, because the setback room had been purged with fresh air for 2 days before sampling and yet 3-octanone was detected. The observed 3-octanone (0.4 ng.liter ${ }^{-1}$ of air) represents freshly synthesized compound.

The air sampled at the MTDF contained many compounds and, apparently, most of these compounds are derived from the background air in the MTDF, because 10-g sam- 
ples of compost did not contain these extra compounds. Some of the background volatiles have been tentatively identified by computer matching techniques and were shown to be present at the MTDF in the absence of the compost. These include ethenyl benzene (styrene), di- and tri-methyl benzenes, benzaldehyde, and a series of hydrocarbons (C12 to C-20).

Air sampling of spawned compost contained in bags. The physical breaking up of the colonized compost (treatments B, C, or D) changes the levels of compound emitted compared to nondisturbed compost treatment A (Fig. 4). Ten grams of colonized compost emitted (treatment B) 200 and $1100 \mathrm{ng}$ of 3octanone and 1-octen-3-ol, respectively, during a 15 -min sampling period, whereas 5 $\mathrm{kg}$ of intact colonized compost only gave off 600 and $100 \mathrm{ng}$, respectively, over $9 \mathrm{~h}$ of sampling. The average amount of 3-octanone released in treatment $\mathrm{A}$ was $600 \mathrm{ng}$ as compared to $1500 \mathrm{ng}$ in treatment $\mathrm{C}$ and $29,600 \mathrm{ng}$ in treatment $\mathrm{D}$. The mean amount of 1-octen-3-ol released in treatment A was $100 \mathrm{ng}$ as compared to $10,800 \mathrm{ng}$ in treatment $\mathrm{C}$ and $9900 \mathrm{ng}$ in treatment $\mathrm{D}$.

The CAC layer and the soybean supplement both influenced the production and/or release of 3-octanone and 1-octen-3-ol (Fig. 4). The addition of a CAC layer after the colonized compost had been mixed reduced the amount of 3-octanone from 29,600 (treatment D) to $12,800 \mathrm{ng}$ and the amount of 1-octen-3-ol from 9900 (treatment D) to $600 \mathrm{ng}$. The 3-octanone : 1-octen-3-ol ratio in treatment $\mathrm{D}$ was $3: 1$ as compared to $21: 1$ in treatment $\mathrm{E}$.

There was considerable reduction in the release and/or production of 3-octanone and 1-octen-3-ol if soybean supplement was mixed with the colonized compost and then CAC (treatment F, Fig. 4). The amount of 3-octanone was reduced from an average of 29,600 (treatment D) to $1900 \mathrm{ng}$ (treatment F), and the average amount of 1-octen-3-ol emitted decreased from 9900 to $100 \mathrm{ng}$. The 3:1 ratio of 3-octanone : 1-octen-3-ol in treatment D was changed to $15: 1$ in treatment $F$.

The evolution of 3-octanone and 1-octen3-ol from the bagged colonized compost was evaluated over time. At 16 days after spawning, neither 3-octanone nor 1-octen-3-ol were detected. At 21 days after spawning, detectable amounts of 3-octanone and 1-octen-3ol were emitted in about a 5:1 ratio in bags that were not disturbed or mixed. The results from the addition of the CAC layer at 16 days have been discussed above. The bags were sampled at 4 or 6 days after CAC and 3-octanone was detected in very low amounts or not detected, whereas 1-octen-3-ol was not detected.

The CAC layer caused a relatively large amount of 3-octanone and a lesser amount of 1-octen-3-ol to be released from mixed colonized compost at 21,23 , or 25 days after spawning. A decrease in the two compounds occurred several days after CAC, which was also observed at the MTDF.

Addition of Spawn Mate to spawned compost contained in bags. Both spawned compost treatments contained in bags emitted 3octanone by 9 to 10 days after spawning (Fig. 5 ), whereas 3-octanone was not detected until 12 to 13 days after spawning at the MTDF. The amounts of 3-octanone emitted were similar between the two spawned compost treatments for the two sampling periods before CAC and the period after CAC. The spawned compost without Spawn Mate emitted 1-octen-3-ol after 14 days. This did not occur in the spawned compost with Spawn Mate. The amounts of 1-octen-3-ol released after CAC were similar between the two treatments.

The greatest attraction of $M$. halterata to spawned compost is reported at 11 to 14 days after spawning (Hussey, 1959). Two compounds, 3-octanone and 1-octen-3-ol, were detected in the air of the MTDF at only 12 to 13 days after spawning in crops 1 and 2 . This result differs from Grove and Blight's (1983) finding that the two compounds did not change in concentration during the same period of time. Of all the compounds detected in the MTDF air, 3-octanone and 1octen-3-ol were clearly of fungal origin based on the GC-MSD analysis of $10 \mathrm{~g}$ of spawned compost. The same amount of spawned compost was used in the fly bioassays where attraction to the spawned compost was demonstrated (Pfeil, 1990). This relationship implies that 3-octanone and 1-octen-3-ol may be involved in the observed attraction; however, bioassays of pure compounds did not substantiate this hypothesis (Pfeil, 1990).

The amounts of volatiles emitted from a 10-g sample of spawned compost that was broken apart is not representative of intact spawned compost. The difference in the results may be due to considerably more $\mathrm{O}_{2}$ being passed over the 10 -g sample than can occur in a bag. Oxygen is required for the enzymatic degradation of linoleic acid, the proposed precursor to the two compounds (Wurzenberger and Grosch, 1984a).

In light of the results from the CAC of the crops at the MTDF, the bag experiment helped clarify factor(s) influencing the production and/or release of 3-octanone and 1-octen-3ol. The CAC layer by itself and in conjunc- tion with the soybean supplement would reduce the amounts of the two compounds released from CAC spawned compost.

The physical breakup of spawned compost releases both 3-octanone and 1-octen-3-ol. We assume that the rupturing of fungal cells releases the enzymes that split the supposed precursor, linoleic acid, to form the volatiles. If this assumption is correct, then the release of the two volatiles 12 to 13 days after spawning may be due to the release of degradative enzymes caused by death of the fungus. Thus, the release of the two compounds may be an indicator of the quality of the colonized compost. The peatmoss layer spread onto spawned compost at CAC does moderate the amounts of 3-octanone and 1octen-3-ol released and there appears to be a selective absorption of 1-octen-3-ol by the peatmoss.

\section{Literature Cited}

Barber, W. and R. Cantarera. 1987. When phorids get in your eyes. Mushroom News August:16-19.

Grove, J.F. and M.M. Blight. 1983. The oviposition attractant for the mushroom phorid $M e$ gaselia halterata: The identification of volatiles present in mushroom house air. J. Sci. Food Agr. 34:181-185.

Hussey, N.W. 1959. Biology of mushroom phorids. Mushroom Sci. 4:260-270.

Hussey, N.W. 1961. Recent work on the control of the Worthing phorid. Mushroom Growers Assn. Bul. 144:495-502.

Moreton, B.D. 1954. The phorid. No real evidence of acquired resistance. Mushroom Growers Assn. Bul. 50:62-65.

Pfeil, R.M. 1990. The attraction of Megaselia halterata (Wood) (Diptera:Phoridae) to spawned compost and the analysis of volatiles from compost colonized by the commercial mushroom, Agaricus bisporus (Lange) Imbach (Fungi:Agaricaceae). PhD Diss., The Pennsylvania State Univ., University Park.

Schisler, L.C. 1982. Biochemical and mycological aspects of mushroom composting, p. 3-9. In: P.J. Wuest (ed.). Penn State handbook for commercial mushroom growers. The Pennsylvania State Univ., University Park.

Wurzenberger, M. and W. Grosch. 1982. The enzymatic oxidative breakdown of linoleic acid in mushrooms (Psalliota bispora). Z. Lebensm. Unters.-Forsch. 175:186-190.

Wurzenberger, M. and W. Grosch. 1984a. Origin of the oxygen in the products of the enzymatic cleavage reaction of linoleic acid to 1-octen-3ol and 10-oxo- trans- 8-decenoic acid in mushrooms (Psalliota bispora). Biochem. Biophysiol. Acta 794:18-24.

Wurzenberger, M. and W. Grosch. 1984b. The formation of 1-octen-3-ol from the 10-hydroperoxide isomer of linoleic acid by a hydroperoxide lyase in mushrooms (Psalliota bispora). Biochem. Biophysiol. Acta 794:25-30. 